Brit. J. industr. Med., 1953, 10, 69.

\title{
RESPIRATORS FOR PROTECTION AGAINST MERCURY VAPOUR*
}

\author{
BY \\ V. B. VOUK, Z. TOPOLNIK, and M. FUGA ̌ \\ From the Institute of Industrial Hygiene, Zagreb, Yugoslavia
}

\begin{abstract}
Although the primary consideration in controlling a mercury vapour hazard should be engineering measures preventing the air from becoming contaminated, or eliminating the contaminant from the air, there are always many operations or working places where the application of these methods is impracticable or too costly ; for instance, charging furnaces or cleaning the main stack or condensers in a mercury smelting plant. In such kinds of work the engineering control must be supplemented or substituted by personal protective measures such as the use of air line respirators or respirators of the air-purifying type.

Before detailed consideration is given to the design and testing of respirators for mercury vapour it is necessary to discuss the adsorption, physical adsorption as well as chemisorption, of mercury vapour.
\end{abstract}

\section{Physical Adsorption of Mercury Vapour on Porous Substances}

It is well known that pressure and temperature have an effect on the amount of gas or vapour adsorbed on porous substances. Zelinsky and Rakusin (1926) investigated by a static method the adsorption equilibrium of mercury vapour on birchwood charcoal and found that it adsorbed considerable quantities of mercury. Coolidge (1927), however, who also used a static method, found that the adsorption of mercury vapour on activated coconut charcoal was negligible except at elevated temperatures. At $480^{\circ} \mathrm{C}$. the maximum adsorption was $16.2 \mathrm{mg}$. per g. for a pressure of $730 \mathrm{~mm}$. With decreasing pressure and temperature the amount adsorbed also decreased. At $100^{\circ} \mathrm{C}$. and a pressure of $0.28 \mathrm{~mm}$. the adsorbed quantity was only $2.7 \mathrm{mg}$. per g. At $20^{\circ} \mathrm{C}$. he calculated (assuming the validity of Henry's law) that the

\footnotetext{
* A paper read at the tenth International Congress of Industrial Medicine, Lisbon, in September, 1951.
}

maximum adsorption was $0.3 \mathrm{mg}$. per g. The calculated heat of adsorption $(8,900$ cal. per mole.), although lower than the heat of evaporation of mercury, was still greater than the heat of adsorption of many other gases. Thus the transfer of mercury atoms from the liquid phase to charcoal is endothermic and, therefore, favoured by high temperatures. On the other hand the transfer of mercury atoms from the gaseous phase to the adsorbent is exothermic and should proceed with ease at lower temperatures if no liquid mercury were present. It seems that the old model of capillary condensation, although not generally accepted, can help us to understand why this does not happen. The pressure driving a liquid into the capillaries of a porous substance is given by

$$
P=\frac{2 \gamma_{L} \cos \theta_{\Lambda}}{r}
$$

where $r$ is the radius of the (cylindrical) capillary, $\gamma_{L}$ the surface tension of the liquid and $\theta_{A}$ the advancing contact angle (see e.g. Adam, 1948). For mercury $\gamma_{\mathrm{L}}$ is large $\left(487\right.$ dynes $/ \mathrm{cm}$. at $15^{\circ} \mathrm{C}$.) and therefore $\theta_{\mathrm{A}}>90^{\circ}$. This means that the pressure must be applied to drive liquid mercury into the pores of the charcoal, and hence the capillary condensation cannot take place spontaneously.

The results obtained by Coolidge have been confirmed also by other authors. Table 1 summarizes the experimental results of the measurement of static and dynamic adsorption of mercury vapour on various adsorbents.

\section{Chemisorbents for Mercury Vapour}

The list of various chemisorbents for mercury vapour recommended for use in respirators is long. However from the study of the literature it appears that none of them is better than iodized charcoal. We found that silica gel impregnated with iodine and copper iodide, the chemisorbent proposed by 
TABLE 1

COMPARISON OF VARIOUS DATA ON PHYSICAL ADSORPTION OF MERCURY VAPOUR

\begin{tabular}{|c|c|c|c|c|}
\hline Adsorbent & Author & $\begin{array}{c}\text { Adsorp- } \\
\text { tion } \\
\text { (mg. } \\
\text { per g.) }\end{array}$ & $\begin{array}{c}\text { Tempera- } \\
\text { ture } \\
\left(0^{\circ} \mathrm{C} .\right)\end{array}$ & Method \\
\hline Birchwood & $\begin{array}{l}\text { Zelinsky and } \\
\text { Rakusin (1926) }\end{array}$ & $46 \cdot 9$ & 20 & Static \\
\hline Activated coconut & Coolidge (1927) & $0 \cdot 3$ & 20 & Static \\
\hline German gas-mask & Shiels (1929) & $0 \cdot 2$ & $12-14$ & Static \\
\hline Anticarbone A & Mora Agües & 0.4 & 20 & Dynamic \\
\hline Animal "charcoal, & Alekseevskii & $0.6^{\circ}$ & 20 & Static \\
\hline $\begin{array}{c}\text { Activated charcoal } \\
\text { (Kahlbaum) }\end{array}$ & $\begin{array}{c}\text { Alekseevskii } \\
(1933)\end{array}$ & 0.4 & 20 & Static \\
\hline $\begin{array}{c}\text { American } \\
\text { "charcoal " }\end{array}$ & Alekseevskii & 0.4 & 20 & Static \\
\hline Activated $\mathrm{A}_{2} \mathrm{O}_{3}$ & Alekseevskii & Traces & $2 C$ & Static \\
\hline Chabazite* & $\begin{array}{l}\text { Barrer and } \\
\text { Woodhead (1948) }\end{array}$ & $1 \cdot 0$ & 100 & Static \\
\hline
\end{tabular}

*Chabazite is a hydrated silicate of aluminium, calcium, and potassium belonging to the zeolite group.

Yavorovskaya (1946), was not stable enough, for, when stored for three to four months, it gave off iodine. The preparation of manganese dioxide, another proposed chemisorbent of good qualities, is rather complicated. Iodized charcoal, on the other hand, has all the advantages of simple preparation, stability, and good protective power, and it was therefore decided to use it in further experiments.

The first proposal for using iodized charcoal as a chemisorbent for mercury vapour came from Stock $(1931,1934)$. Various methods have been described for the preparation of iodized charcoal. Most of them consist in the treatment of active charcoal with a solution of iodine in various solvents such as ethanol (DEGEA, 1933), benzene, carbon disulphide, chloroform, or an aqueous solution of potassium iodide. The adsorptive power of iodized charcoal depends on the method of preparation. It increases with the kind of solvent used in the following order: ethanol, benzene, carbon disulphide, aqueous solution of potassium iodide, chloroform (Pyankov, 1936). The difference in adsorptive power resulting from the use of different solvents for iodine is more pronounced the greater the concentration of mercury vapour reacting with the chemisorbent. The concentration of iodine should amount to approximately $5 \%$ by weight of charcoal (Pütter and Hirsch, 1934). If the iodine concentration falls below this value the adsorptive power decreases rapidly. Higher concentrations of iodine are not suitable owing to the possibility of desorption.

The fact that iodized charcoal adsorbs chemically more than twice the expected amount of mercury vapour is remarkable (Pyankov, 1936). It is probably connected with the method by which the charcoal is activated. The substance used in its preparation, such as chlorine or zinc chloride, may react chemically with the mercury vapour.

For practical purposes dynamic adsorption of mercury vapour on iodized charcoal is important. The life time or resistance time $\left(t_{R}\right)$ is defined as the time necessary for mercury vapour of a given concentration, carried by an air stream, to penetrate a layer of adsorbent. It depends on the thickness of the layer, the concentration of iodine on charcoal, the concentration of mercury vapour in the air stream, the linear velocity of the air stream, to which the time of contact of mercury atoms and iodine is inversely proportional, temperature, the grain size of the adsorbent (Yavorovskaya, 1946), and the previous treatment of the charcoal.

Pyankov (1937) found that the equation

$$
\mathrm{t}_{\mathrm{R}}=\mathrm{t}_{0}+\mathrm{K}\left(\mathrm{L}-\mathrm{L}_{\mathbf{0}}\right)
$$

holds for iodized charcoal. Here $\mathrm{L}$ is the thickness of the adsorbing layer, and $t_{0}, K$, and $L_{0}$ are constants. This is a special case of the well known Mecklenburg's (1925) relation.

The relation between the concentration of mercury vapour, the concentration of iodine on active charcoal, and the velocity of air may be represented by the empirical equation

$$
\mathrm{t}_{\mathrm{R}}=\alpha \cdot \mathrm{c}_{\mathrm{I}} / \mathrm{c}_{\mathrm{Hg}} \cdot 1 / \mathrm{w}
$$

where $\alpha$ is a numerical factor (Pyankov, 1937), $c_{I}$ and $c_{\mathrm{H}_{\mathrm{s}}}$ are the concentrations of iodine and mercury respectively and $\mathrm{w}$ is the velocity in cu.m. per minute, the cross-section area and thickness of the iodized charcoal layer being constant.

The effect of temperature within limits important for practical applications is negligible.

The efficiency of chemisorbents increases with decreasing grain size (Yavorovskaya, 1946).

When estimating the efficiency of a given activated charcoal as a filtering material it is important to consider the treatment that it has undergone, i.e. the method of initial activation. Grosskopf (1938) showed that various industrial filters, not specially designed for use against mercury vapours, offer some protection against this hazard. Thus, e.g., "dräger filter SM483" designed for use against ammonia and $\mathrm{H}_{2} \mathrm{~S}$ had a resistance time of 1,440 minutes when tested at $20^{\circ} \mathrm{C}$. and at a concentration of mercury vapour of $14 \mathrm{mg}$./cu.m.

Owing to the great number of relevant variables it is difficult to compare the experimental results on the resistance time of iodized charcoal as obtained by various workers. As an example of 
experimental data we quote the results of Pütter and Hirsch (1934) who obtained a resistance time of about 100 hours for a special " auer" filter filled with iodized carbon with $3 \%$ iodine, when the air velocity was 30 litres per minute and the mercury concentration approximately $8 \mathrm{mg}$. per cu.m.

\section{A Respirator for Mercury Vapour}

In an attempt to make the working environment in the Idria mines less dangerous to the miners' health, a respirator giving protection against mercury vapour was designed in the laboratories of the Institute of Industrial Hygiene in Zagreb.

The following requirements were set up for an efficient filtering device against mercury vapour:-(1) The filter should be impermeable to mercury vapour up to a concentration of $10 \mathrm{mg}$. per cu.m. of air with a resistance time of at least 250 hours. The concentration limit of $10 \mathrm{mg}$. per cu.m. of air was set on the basis of the air analyses in the Idria mines (Vouk, Fugaš, and Topolnik, 1950) where the maximum concentration of mercury vapour found in normal working places was $5.9 \mathrm{mg}$. per cu.m. Special operations in the smelting plant may present greater hazards ; for example, the workers who clean the main chimney and the condensers may be exposed to concentrations of mercury vapour as high as $30-40 \mathrm{mg}$. per cu.m. But the design of a general purpose air filtering device cannot be based on these extreme conditions. (2) The resistance to breathing, on inhalation, should be less than 6-7 $\mathrm{mm}$. water head at a continuous flow rate of 30 litres per minute (or 25 mm. at 85 litres per minute). (3) The filter should also offer some protection against mercury aerosols. (4) The protective power of the filter should not decrease if stored for long periods of time. (5) Refilling of the canister should be easily performed. (6) It should not interfere with workers' freedom of movement.

Preparation of Iodized Charcoal.-A gas-mask charcoal (grain size $1.5 \mathrm{~mm}$.) was used for the preparation of iodized charcoal; its water extract gave with silver nitrate a strong reaction of chloride ion. The first method used for preparation consisted in treating active charcoal with a $2.5 \%$ alcoholic solution of iodine (Yavorovskaya, 1946) and subsequently drying it at $50^{\circ} \mathrm{C}$. The method gave good results, but it took quite a long time to prepare. Therefore we tried another simple method*. Active charcoal was mixed with solid iodine and kept at $60^{\circ} \mathrm{C}$. and at the same time well stirred until all the iodine was absorbed. The concentration of iodine was $5 \%$ by weight of charcoal. Iodized charcoal prepared in this way was found very satisfactory. It was very stable, did not give off its iodine even on prolonged storage, and had no smell.

Measurement of Resistance Time.-The apparatus for the measurement of resistance time is shown schematically in Fig. 1. A stream of compressed air enters the

* This method was suggested by Mr. Štucin from the Faculty of Medicine, Chemical Department, University of Ljubljana. apparatus through the flow meter $(\mathrm{H})$ and passes the gas-washing bottle $(\mathrm{M})$ containing pure mercury. The washing bottle is equipped with a fritted glass plate (N). The bottle is immersed in the water bath (L) which enables the heating of mercury up to $100^{\circ} \mathrm{C}$. The air saturated or nearly saturated with mercury vapour leaves the washing bottle through the air ejector $(\mathrm{K})$ where it is mixed with the other part of fresh air coming through the flow meter $(\mathrm{J})$. The mixing of the air streams is completed in the bottle (E). From the bottle (E) the air-mercury vapour mixture enters the filter (B). Samples for determination of the concentration of mercury vapour are taken at (D) and (C). Before going to the exhauster the air stream passes the dry gas meter (A) where the total quantity of air passing the filter (litres per minute) is measured once more. Owing to the large difference between the room temperature and the temperature of the water-bath $(\mathrm{L})$, the air saturated with mercury vapour cools down quickly when entering the ejector, and a rapid condensation of mercury vapour takes place which enhances the formation of mercury aerosols. Thus we were in the position also to test the permeability of filters to aerosols with the same apparatus.

Determination of Mercury Concentration in the Air Stream.-The analysis of air samples taken at (D) and (C) was performed by means of a Beckman spectrophotometer, which was specially adapted for this purpose. The ordinary light source of the Beckman instrument was replaced by a low pressure mercury vapour lamp having a maximum radiation output at $2536.5 \mathrm{~A}$; the wavelength knob of the monochromator was also set at $2536 \cdot 5$ A. A $2310-100-89$ cell was filled with the air to be analysed. For this purpose a special filling attachment was used. The optical density of the air sample was then measured. By means of a calibration curve it was possible to estimate with sufficient accuracy concentrations of mercury vapour as low as $0.05 \mathrm{mg}$. per cu.m. of air. Details of the application of the Beckman spectrophotometer for the determination of mercury vapour in air will be published elsewhere.

Results.-A layer of gas-mask charcoal (without iodine) $4 \mathrm{~cm}$. thick was exposed to an air stream carrying 6.2 to $7 \cdot 1 \mathrm{mg}$. per cu.m. of mercury vapour. In all experiments the velocity of the air stream was $200 \mathrm{ml}$. per sq. $\mathrm{cm}$. per minute. This velocity was chosen because it corresponded to a rate of air passage of 30 litres per minute in the final shape of the respirator canister. The resistance time was found to be between 990 and 1,140 minutes.

Experiments carried out in order to find the effect of the concentration of iodine in the active charcoal gave the following results for a $2 \mathrm{~cm}$. layer (Table 2 ).

In order to exclude the influence of mercury aerosols a fibrous filter was inserted in the air stream in front of the iodized charcoal layer. The iodized carbon layer alone was not able to hold up mercury aerosols. The testing was discontinued at 120 hours since Pütter and Hirsch (1934) have recorded 100 hours as the upper limit for $5 \%$ iodized charcoal. 


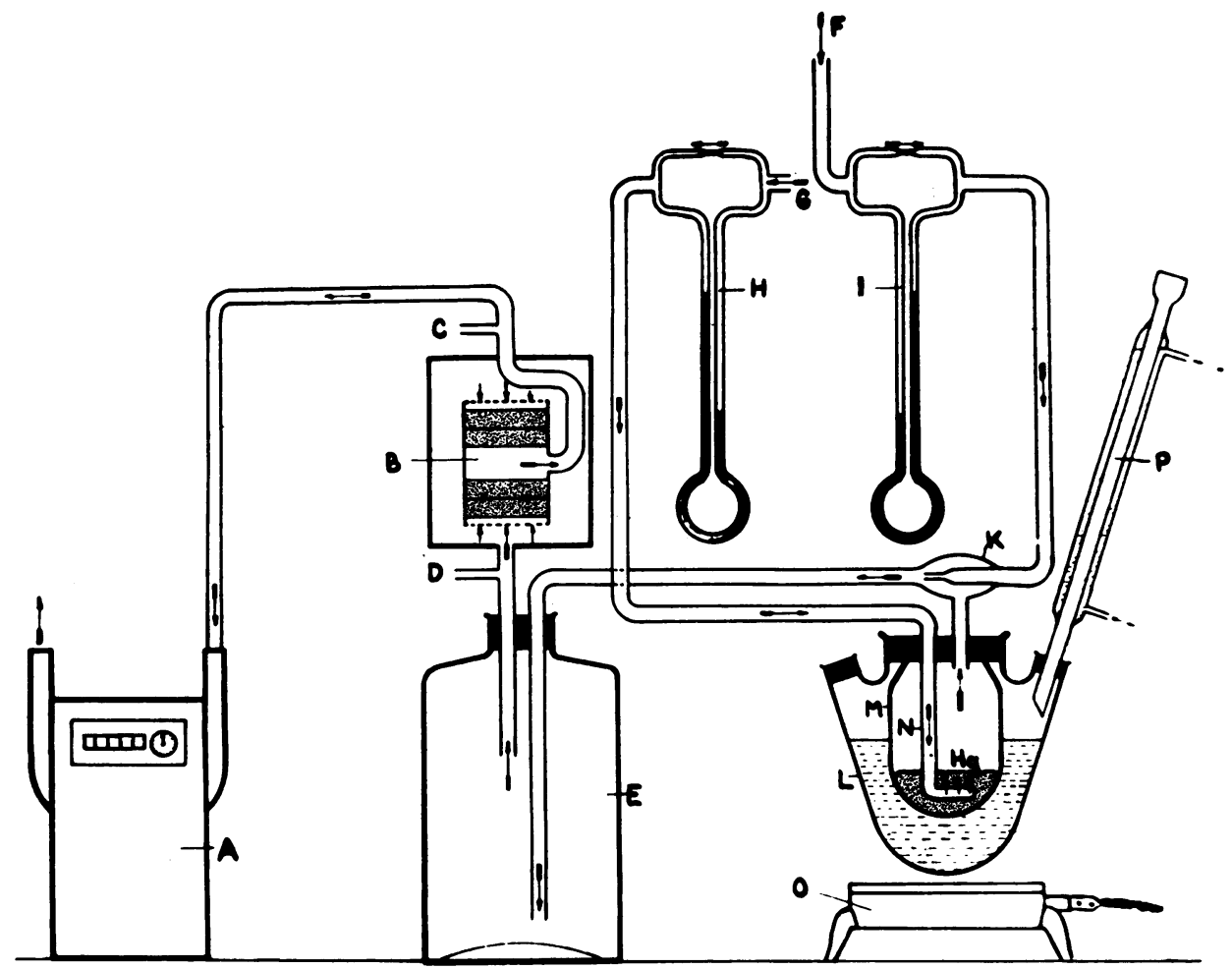

FIG. 1.-Apparatus for measuring the resistance time of filters : (A) dry gas meter, (B) mercury vapour filter, (C,D) outlets for sampling air-mercury vapour mixture, (E) mixing bottle, $(F)$ dilution air inlet, $(G)$ primary air inlet, $(H, I)$ flow meters, $(\mathrm{K})$ air ejector, $(\mathrm{L})$ water bath, $(\mathrm{M})$ gas-washing bottle, $(\mathrm{N})$ glass tube, $(\mathrm{O})$ electric heater, $(\mathrm{P})$ reflux condenser.

TABLE 2

RESISTANCE TIME AS A FUNCTION OF CONCENTRATION OF IODINE

\begin{tabular}{|c|c|c|}
\hline $\begin{array}{l}\text { Percentage of } \\
\text { lodine in } \\
\text { Iodized Carbon }\end{array}$ & $\begin{array}{c}\text { Resistance Time } \\
\text { (hours) }\end{array}$ & $\begin{array}{c}\text { Mercury } \\
\text { Concentration } \\
\text { (mg. per cu.m.) }\end{array}$ \\
\hline $\begin{array}{l}2 \cdot 5 \\
3.5 \\
4 \cdot 0 \\
5.0\end{array}$ & $\begin{array}{r}50 \\
65 \\
80 \\
120\end{array}$ & $\begin{array}{l}5 \text { to } 6.5 \\
=\end{array}$ \\
\hline
\end{tabular}

A series of experimental canisters was then constructed containing (a) a fibrous filter of the "wilson" or "M.S.A." dust respirator type, or a Yugoslav "vevče" paper filter, (b) a $2 \mathrm{~cm}$. layer of iodized charcoal with $5 \%$ iodine, and (c) a $2 \mathrm{~cm}$. layer of untreated gasmask charcoal. The purpose of this last layer was to retain any iodine vapour that might be given off by the layer of iodized charcoal. A specimen of the results of measurement of the resistance time is given in Table 3. The resistance time thus proved to be between 285 and 295 hours. The mercury vapour load on the filter is visible from this table.

Types of Fibrous Filter.-The breathing resistance of experimental canisters was found to depend to a large extent on the quality of the fibrous filter. The resistance of the charcoal layers alone amounted to $2 \mathrm{~mm}$. water head. The best results with regard to the breathing resistance were obtained with an experimental/dust filter produced at the Institute for Cellulose and Paper in Vevče, Ljubljana (Slovenia). The resistance of the complete canister at 30 litres per minute was $5.5 \mathrm{~mm}$. of water (16 mm. at 85 litres per minute). The canister equipped with an M.S.A. dust filter showed a resistance of $7.5 \mathrm{~mm}$. of water at 30 litres per minute. There was no difference in resistance time when the "vevče" filter was used instead of the "wilson" filter. The total cross section of the filter was $150 \mathrm{sq} . \mathrm{cm}$.

\section{Field Testing}

Although the laboratory experiments with filters had given satisfactory results with regard to their protective power against atmospheric mercury and their resistance to breathing, there remained various questions which could be answered only by field testing. Are the respirators comfortable ? Do they interfere with the free movement of workers? What is the workers' attitude towards such personal protective devices? Are they willing to suffer some additional discomfort, which is inevitable, for the 
TABLE 3

MEASUREMENT OF THE RESISTANCE TIME IN EXPERIMENTAL CANISTER NO. 10

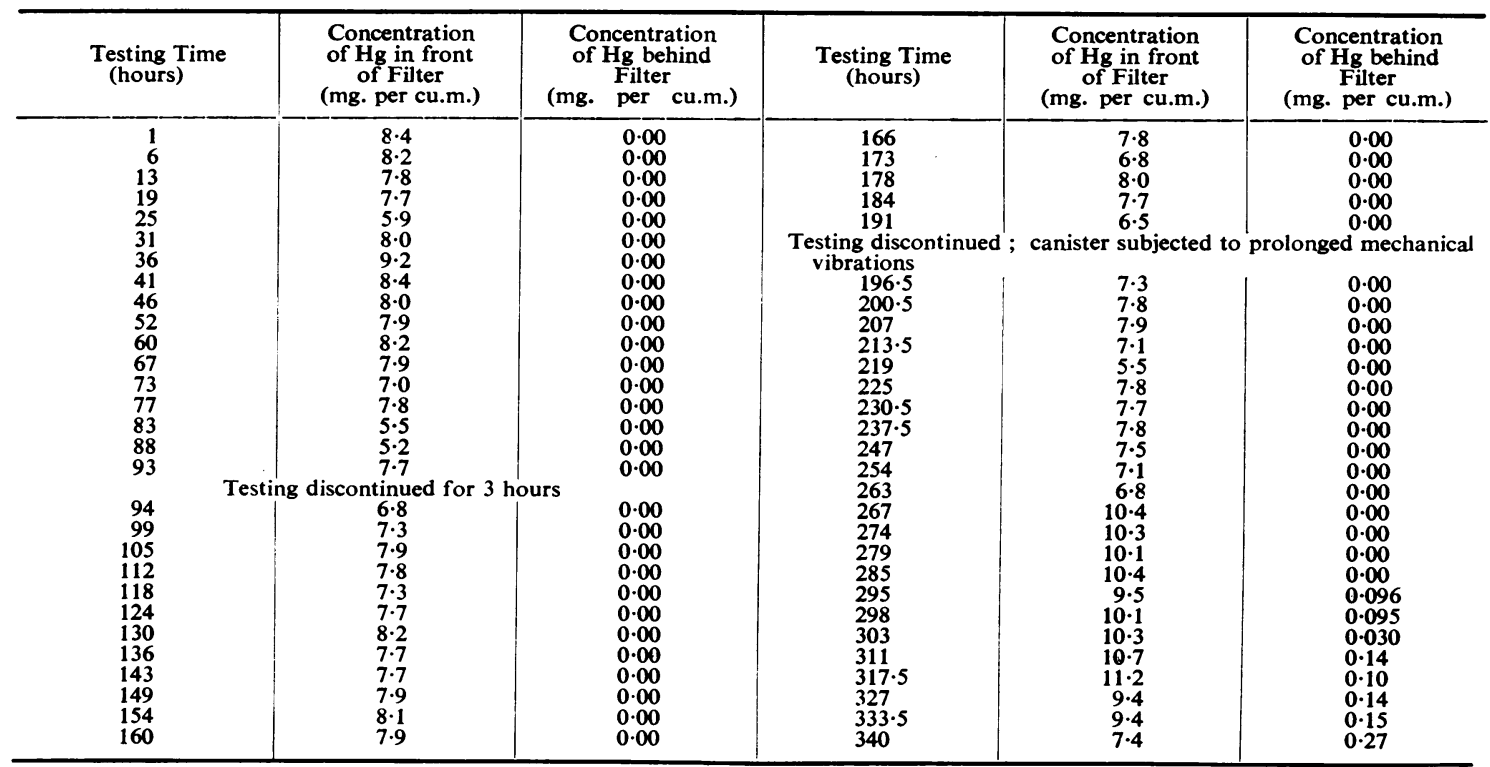

Filling : fibrous filter "Vevče-P $\mathrm{P}_{2}$ "-2 cm. iodized carbon $(5 \%)-2 \mathrm{~cm}$. gas-mask charcoal. (Breathing resistance : $5 \mathrm{~mm}$. water head at 30 litres per minute)

sake of preserving their health? It is very important to obtain at least partial answers to these questions before the use of respirators can be recommended, since the efficiency of such preventive measures depends as much on the subjective factors, such as the care of workers in maintaining the respirators and their discipline in wearing them, as on objective factors, such as impermeability of the filter to the atmospheric contaminant and its breathing resistance. It is obvious that the efficiency of this protective measure will be much less if the workers are coerced to wear the respirators than if they ask for them.

Our preliminary field testing was conducted in the following way. Two working teams were organized in the mines of Idria. The first team consisted of four men wearing respirators (two miners and two members of the Institute of Industrial Hygiene) and one miner working without a respirator. The wearers of the respirators worked 10 days (six hours daily). The miner who was unprotected worked only five days, and was then replaced by another miner who also worked five days. The average concentration of mercury vapour at the working place was 1.2 mg./cu.m. (determined by means of a selenium sulphide detector).

The second team consisted of only two miners wearing respirators. The concentration of mercury vapour at their working place amounted to 2.0 mg./cu.m.

The members of both teams were daily examined by the mine's medical officer. The excretion of mercury in urine was followed only qualitatively using a method described by Pinter and Ruždić (1942)* for detecting mercury in urine.

These preliminary tests gave quite satisfactory results with regard to the protective power of the respirator, but suggested some minor changes in the design of the respirators. None of the wearers of the respirator in the first as well as in the second team showed any clinical symptoms of mercury poisoning to the end of the experiment which lasted 10 days. No mercury was found in the urine. The first miner, a member of the first team, who worked without the respirator started to excrete mercury in urine on the first day, and clinical symptoms of mercury poisoning (stomatitis, gingivitis, salivation combined with erethism, and tremor) developed in the course of five days to such an extent that he had to be replaced. The second miner, who took his place, proved more resistant to the influence of mercury vapour. He also worked five days six hours daily, but the excretion

* This method is based on catalytic decomposition of ferrocyanideions in the presence of mercuric-ion. 
of mercury in urine did not start until the fourth day, and he showed no clinical symptoms of poisoning even on the fifth day when the experiment was discontinued.

Two miners, members of the first team, continued to work wearing respirators for a total of 20 days. They did not show any clinical signs of mercury poisoning or mercury exposure even after that length of time.

After the end of field experiments the six respirators were again subjected to laboratory tests. They were still absolutely impermeable to atmospheric mercury, but their resistance to breathing increased to more than $10 \mathrm{~mm}$. of water head owing to the saturation of the cellulose filter with dust. Thus the filter became unusable though the iodized charcoal filling would have lasted much longer.

On the basis of these experiences in field tests the respirator was redesigned, the filling of the filter remaining the same. Besides some other minor changes the new design provided for ready cleaning and exchange of cellulose filters. The re-designed respirators were again subjected to field testing in the course of seven days (six hours daily).

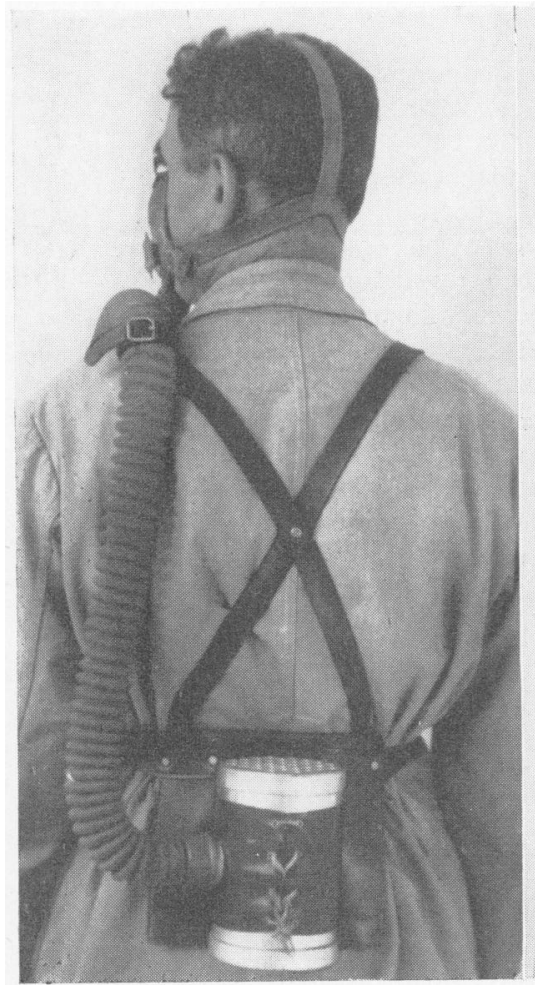

FIG. 3.-Canister harness.

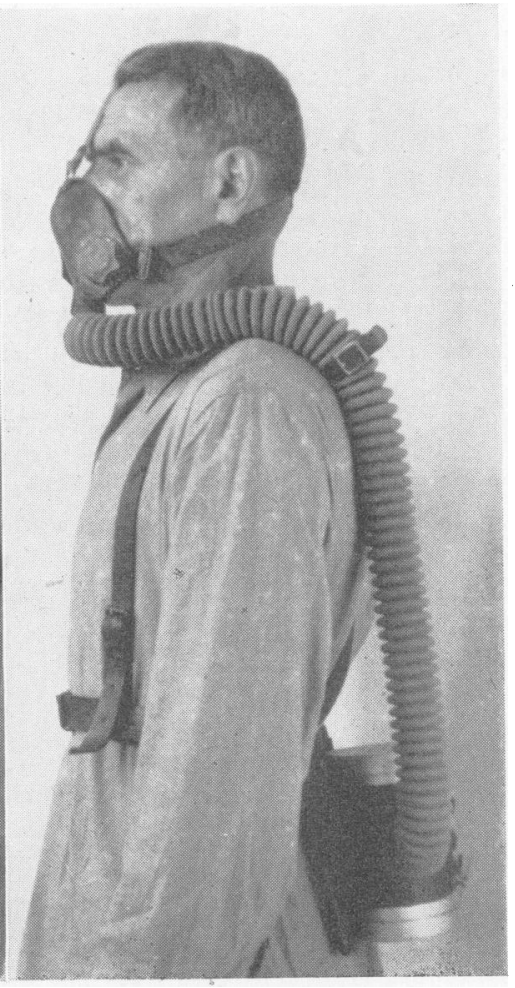

FIG. 4.-Side view.
The selenium sulphide detector showed a concentration of 2.5 mg./cu.m. of mercury vapour (dithizone method gave 4-5 mg./cu.m.) at the working place where the respirators were tested. These experiments again confirmed that the protective power of the respirators was sufficient : none of the miners who wore them showed any clinical symptoms of mercury

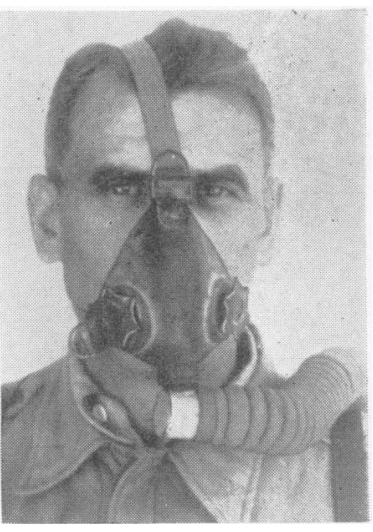

FIG. 2.-Face piece. poisoning. At the end of the experiment the workers were questioned as to the feeling of discomfort caused by wearing respirators, and they unanimously agreed that the respirators were reasonably comfortable and did not appreciably interfere with their free movement. Our impression was that the workers could easily be persuaded to wear respirators at work. Obviously some feeling of discomfort could not be avoided owing to the long wearing period (five to six hours daily). There is no doubt that the respirators do not represent the final solution to the problem of mercury poisoning in the mines but that as a temporary measure they can be used owing to the lack of other measures of controlling this hazard.

On the other hand short-term operations, such as the yearly cleaning of Spirek condensation chambers, represent the type of work for which the respirator is appropriate. Two men employed in cleaning condensation chambers used respirators for six days (five hours daily). They showed no clinical symptoms of mercury poisoning nor any signs of exposure to mercury vapour although the concentration of atmospheric mercury ranged from 16.2 to $18.5 \mathrm{mg}$. $/ \mathrm{cu} . \mathrm{m}$. Because of the extremely high concentration of mercury vapour the thickness of the iodized charcoal layer was increased to $4 \mathrm{~cm}$. and the iodine concentration in the charcoal to $10 \%$.

We are aware that these preliminary field experiments do not furnish sufficient evidence to pass a definite judgment on the suitability of respirators, 
but we believe that they justify any experiment on a larger scale.

\section{The Final Form of the Respirator}

The facepiece (Fig. 2) is similar to that of the M.S.A. " comfo" respirator. It is connected by a

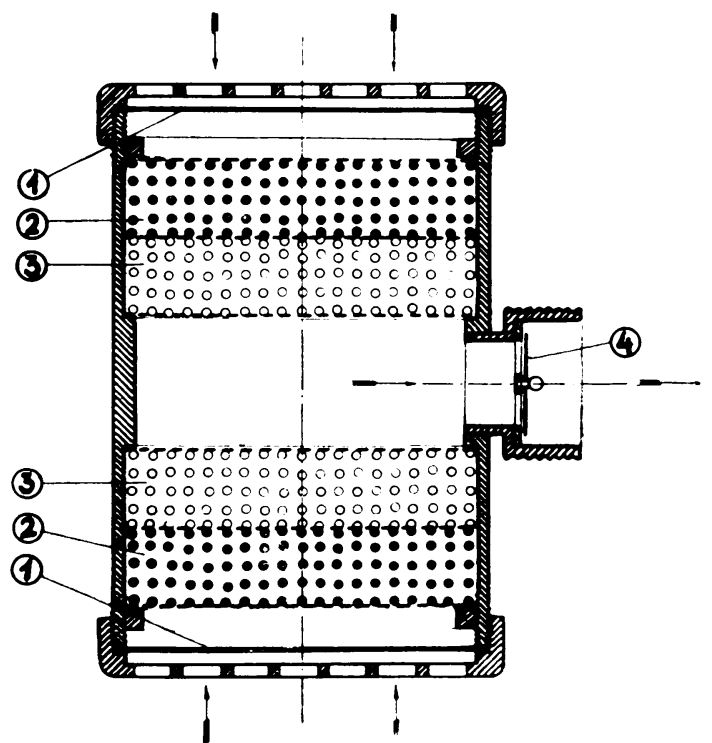

FIG. 5.-Filter in cross-section : (1) fibrous filter, (2) iodized charcoal layer, (3) gas-mask charcoal, (4) inhaling valve.

flexible corrugated rubber tube to the canister which is carried on the back. The arrangement of the harness can be seen in Figs. 3 and 4. The facepiece has two exhaling valves in order to reduce the exhaling resistance to the least possible value. The "starlike" valves are visible in Fig. 2.

The canister in cross section is shown in Fig. 5. It consists of two identical valves containing a fibrous filter, a layer $(2 \mathrm{~cm}$.) of iodized carbon and a layer $(2 \mathrm{~cm}$.) of gas-mask charcoal. The two air streams merge into one in the central tube connected to the corrugated rubber tubing. This design was adopted in order to achieve the minimum breathing. resistance. Approximate dimensions of the canister are : diameter, $10 \mathrm{~cm}$., length, $16 \mathrm{~cm}$. The canister may be opened at both ends by unscrewing the perforated lids so that the fibrous filter and the filling may easily be exchanged. The canister weighs about $800 \mathrm{~g}$. One filling consists of $300 \mathrm{~g}$. of iodized and $300 \mathrm{~g}$. of untreated gas-mask charcoal.

\section{REFERENCES}

Adam, N. K. (1948), Disc. Faraday Soc., No. 3, p. 5. Adam, N. K. (1948). Disc. Faraday Soc., No. 3, p. 5. 360 Barrer, R. M., and Woodhead, M. (1948). Trans. Faraday Soc.,

44, 1001. (1927). J. Amer. chem. Soc., 49, 1949.

Deutsche Gasglühlicht-Auer-Gesellschaft. m.b. H. Berlin (DEGEA). (1933). German Patent No. 588531. Nov. 20.

Grosskopf, K. (1938). Draeger Bull. (Draeger-Hft), No. 197, p. 3895.

Mecklenburg, W. (1925). Z. Elektrochem., 31, 488.

Mora Agües, A. (1932). An. Soc. esp. Fis. Quim., 30, 260.

Pinter, T., and Ruždić, I. (1942). Liječn. Vijesn., 64, 48.

Pyankov, V. A. (1936). J. gen. Chem., Mcscow, 6, 1528.

Pyankov, (1937). Ibid., 7, 198.

Pütter, K. E., and Hirsch, M. (1934). Angew. Chem., 47, 184.

Shiels, D. O.'(1929). J. phys. Chem., 33, 1398.

Stock, A. (1931). Naturwissenschaften, 19, 499.

(1934). Angew. Chem., 47, 64.

Vouk, V. B., Fugaš. M., and Topolnık, Z. (1950). British Journal of Industrial Medicine, 7, 168.

Yavorovskaya, S. F. (1946). Hyg. \& Sanit., Moscow, 11, No. 6,

Zelinsky, N. D., and Rakusir, M. (1926). Ber. dtsch. chem. Ges., 59, 2072. 